\title{
Explorando Estratégias Diferenciadas na Resolução de Problemas Matemáticos
}

\author{
Exploring Different Strategies for Solving Mathematical Problems
}

\author{
Virginia Furlanetto ${ }^{a}$; Maria Madalena Dullius*b \\ ${ }^{a}$ Escola Municipal de Ensino Fundamental Roman Ross. RS, Brasil. \\ ${ }^{\mathrm{b}}$ Universidade do Vale do Taquari. RS, Brasil. \\ *E-mail: madalena@univates.br.
}

\begin{abstract}
Resumo
O ensino e aprendizagem da Matemática tem sido alvo de recorrente preocupação por parte de professores e gestores, pois os resultados alcançados pelos estudantes tem se demonstrado pouco satisfatórios no cenário nacional, como um todo, salvo algumas exceções. Na área da educação Matemática, faz-se necessário melhorar a qualidade do ensino e aprendizagem dos alunos e visando contribuir nesse aspecto, desenvolvemos uma pesquisa com o objetivo de explorar o uso de diferentes estratégias de resolução de problemas matemáticos com estudantes da Educação Básica e verificar como estas interferem nesse processo. Iniciamos o trabalho com um estudo bibliográfico sobre as estratégias de resolução de problemas e investigamos quais delas são utilizadas pelos alunos da Educação Básica. Considerando os dados coletados, desenvolvemos uma intervenção pedagógica com alunos de $7^{\mathrm{a}}$ e $8^{\mathrm{a}}$ séries do Ensino Fundamental, em que exploramos problemas de livros didáticos, Olimpíadas Matemáticas e outras fontes, incentivando a utilização de estratégias alternativas ao Cálculo formal e compartilhando-as por meio de discussões para validação das mesmas. Ao final deste período, foram propostas uma nova seleção de problemas e a participação em uma entrevista semiestruturada, por meio das quais foram obtidos indícios de eficácia da proposta. Os participantes passaram a utilizar com maior frequência e eficácia estratégias alternativas ao Cálculo formal e manifestaram preferência por estas formas de resolução. Apresentamos, portanto, uma possibilidade para o trabalho com resolução de problemas, capaz de auxiliar os estudantes a obterem êxito no processo, de forma autônoma.
\end{abstract}

Palavras-chave: Estratégias. Resolução. Problemas. Matemática. Aprendizagem.

\begin{abstract}
Mathematics teaching and learning have been a permanent concern for teachers and managers since the results that students achieved have not been completely satisfactory nationally. Regarding to Mathematics education improving students' education quality and learning is essential. As a contribution a survey aiming to explore the use of different strategies for solving mathematical problems with students of Elementary School and how they interfere in the process was carried out. It was initially carried out a bibliographical study about problem resolution strategies followed by the investigation on which strategies were used by Elementary school students. Taking into consideration data collected a pedagogical intervention was developed with 7th and 8th grade students of Elementary school aiming to explore textbook problems, Mathematical Olympics and other sources, encouraging the use of alternative strategies to formal calculation and exchanging them to assure their validation. Finally a new problem selection and the participation in a semi-structured interview were proposed and the indication of an effective proposal was carried out. Participants started to use alternative strategies more frequently and more effectively. Therefore we present the possibility for problem resolution development which may help the students to autonomously succeed in the process.
\end{abstract}

Keywords: Strategies. Resolution. Problems. Mathematics. Learning.

\section{INTRODUÇÃO}

A Matemática é, geralmente, uma disciplina considerada difícil pelos estudantes e uma recorrente preocupação dos professores, no que diz respeito ao desempenho escolar. Os números divulgados acerca dos resultados obtidos pelos alunos em avaliações da qualidade da educação apresentam indicativos da preocupante situação em que se encontra a aprendizagem da Matemática no Brasil. Diante desta situação, tem-se como desafio melhorar a qualidade da educação de nossos alunos e para que isso ocorra é preciso ter claro o que se quer que eles aprendam e o que e como ensinar para que essas aprendizagens realmente aconteçam.

Visando fomentar estudos e pesquisas no sentido de qualificar a Educação Básica no Brasil, a CAPES/INEP
(Coordenação de Aperfeiçoamento de Pessoal de Nível Superior/Instituto Nacional de Pesquisas Educacionais Anísio Teixeira) lançou o Edital 038/2010/CAPES/INEP, do Programa Observatório da Educação. No Centro Universitário UNIVATES, Lajeado/RS, foi desenvolvido um projeto, no âmbito deste edital, vinculado ao Mestrado Profissional em Ensino de Ciências Exatas. $\mathrm{O}$ foco do projeto é o desenvolvimento de ações de intervenção pedagógica, a partir de estudos realizados, que possam contribuir para a melhoria da qualidade da Educação Básica brasileira, elevando assim os índices obtidos pelos alunos em avaliações em larga escala. A partir de investigações acerca dos sistemas avaliativos Prova Brasil e SAEB (Sistema Nacional de Avaliação da Educação Básica) verificamos que a prova de Matemática possui como foco principal a resolução de problemas, tornando-se 
este o tema de um estudo, que constituiu-se na dissertação de mestrado da primeira autora, inserido no contexto das intervenções pedagógicas propostas pelo Observatório da Educação e apresentado neste artigo.

Os Parâmetros Curriculares Nacionais (PCN's) (Brasil, 1998, p. 40) sinalizam que, "no processo de ensino e aprendizagem, conceitos, ideias e métodos matemáticos devem ser abordados mediante a exploração de problemas" e apresentam a resolução destes como objetivo relacionado à grande parte dos conteúdos sugeridos para as várias etapas do Ensino Fundamental. Considerando que a resolução de um problema implica a compreensão do que foi proposto e a apresentação de respostas, aplicando procedimentos adequados, cabe ressaltar que existem vários caminhos para se chegar a um mesmo resultado, ou seja, inúmeras são as estratégias que o estudante pode utilizar nesse processo.

A temática das estratégias que podem ser utilizadas na resolução de problemas matemáticos nos sensibiliza, já que percebemos, em nossa trajetória docente, a facilidade com que alguns alunos, quando lhes é permitido, resolvem determinados problemas utilizando estratégias alternativas, mesmo que conteúdos específicos estejam em desenvolvimento. Nesses casos, é comum justificarem que consideram mais fácil resolver de tal forma, que o Cálculo formal, entendido como o algoritmo convencional, relacionado ao conteúdo envolvido no problema, é mais trabalhoso e, geralmente, suas resoluções são coerentes com o problema proposto.

Em contrapartida, percebemos em estudo anterior (Dullius et al., 2011), realizado a partir de resoluções apresentadas por estudantes do Ensino Médio à uma prova de Olimpíada Matemática realizada na UNIVATES, a forte tendência dos participantes ao uso do Cálculo formal. Este, entretanto, nem sempre significa garantia de êxito e pode levar a um caminho mais longo e difícil na busca pela solução.

Diante do exposto, justificamos o desenvolvimento da pesquisa aqui apresentada, que diz respeito à investigação da possível influência da utilização de diferentes estratégias de resolução de problemas, por parte de alunos da Educação Básica, para que obtenham êxito ao deparar-se com essas situações matemáticas. Nesse sentido, tivemos como objetivo explorar o uso de diferentes estratégias de resolução de problemas matemáticos com estudantes da Educação Básica e verificar como estas interferem nesse processo.

Para tanto, desenvolvemos uma intervenção pedagógica onde, inicialmente, oito turmas de $8^{\text {a }}$ série foram convidadas a resolver uma seleção de oito problemas relacionados à Prova Brasil e SAEB. As resoluções foram analisadas sob a perspectiva das diferentes estratégias passíveis de serem utilizadas na solução de problemas matemáticos. Em seguida, em uma das escolas, foram realizados encontros com alunos de $7^{\mathrm{a}}$ e $8^{\mathrm{a}}$ séries do Ensino Fundamental, baseados na resolução de problemas matemáticos, em grupos ou individualmente, incentivando o uso de diferentes estratégias de resolução de problemas e socializando as que foram apresentadas pelos participantes da coleta de dados inicial ou desenvolvidas pelos pesquisadores envolvidos. De natureza predominantemente qualitativa, esta investigação caracteriza-se em um estudo de caso.

\section{Material e Métodos}

Os pressupostos teóricos que nortearam o desenvolvimento desta investigação estão fundamentados na abordagem da Matemática através da resolução de problemas com foco na utilização de diferentes estratégias.

Onuchic e Allevato (2004, p. 213) destacam que "a Matemática têm desempenhado um papel importante no desenvolvimento da sociedade e que problemas de Matemática têm ocupado um lugar central no currículo escolar desde a Antiguidade". Para as autoras, a atividade matemática está cada vez mais presente em nosso contexto diário e no mundo do trabalho, fazendo-se necessário saber utilizá-la cada vez mais e melhor. Entretanto, esta disciplina que parece estar tão vinculada às nossas atividades diárias e à maioria das profissões, possui elevadas taxas de insucesso por parte dos alunos, como podemos perceber, por exemplo, nos resultados de avaliações externas, como a Prova Brasil e SAEB.

Nesse contexto, a abordagem da Matemática através da resolução de problemas pode contribuir na formação de cidadãos mais autônomos e críticos à medida que o aluno se torna agente de sua própria aprendizagem, criando seus métodos e estratégias de resolução em contrapartida a metodologias mais tradicionais, onde predomina a memorização e mecanização. Dante assinala que:

Mais do que nunca precisamos de pessoas ativas e participantes, que deverão tomar decisões rápidas e, tanto quanto possível, precisas. Assim, é necessário formar cidadãos matematicamente alfabetizados, que saibam como resolver, de modo inteligente, seus problemas de comércio, economia, administração, engenharia, medicina, previsão do tempo e outros da vida diária. E, para isso, é preciso que a criança tenha, em seu currículo de matemática elementar, a resolução de problemas como parte substancial, para que desenvolva desde cedo sua capacidade de enfrentar situações-problema (Dante, 2000, p. 15).

Além disso, a Matriz de Referência do SAEB e da Prova Brasil, avaliações estruturadas com foco em resolução de problemas, destaca que "o conhecimento matemático ganha significado, quando os alunos têm situações desafiadoras para resolver e trabalham para desenvolver estratégias de resolução" (Brasil, 2008, p. 106).

Quanto à resolução de problemas, D’Ambrósio (n.d) ressalta que, muitas vezes, os alunos desistem de solucionar um problema matemático por não ter aprendido como resolver esse tipo de questão, ou seja, por que não conhecem o algoritmo ou processo de solução que o professor espera que ele desenvolva para aquele problema. Segundo a autora, 
"falta aos alunos uma flexibilidade de solução e a coragem de tentar soluções alternativas, diferentes das propostas pelos professores" (D’Ambrósio, n.d, texto digital). Este tipo de atitude pode demonstrar receio por parte dos alunos em tentar soluções diferentes daquelas que lhes são propostas em sala de aula, o que inibe o desenvolvimento de características muito importantes à formação cidadã e ao mundo do trabalho, como a criatividade, a autonomia e o senso crítico.

A respeito disso, Cavalcanti (2001, p. 126) ressalta que, a valorização das estratégias utilizadas:

[...]inibe atitudes inadequadas em relação à resolução de problemas, como, por exemplo, abandonar rapidamente um problema quando a técnica envolvida não é identificada, esperar que alguém o resolva, ficar perguntando qual é a operação que resolve a situação, ou acreditar que não vale a pena pensar mais demoradamente para resolver um problema.

No entendimento de Musser e Shaughnessy (1997, p. 188), a ênfase do currículo da Matemática na escola do passado era a aprendizagem de algoritmos, devido ao forte domínio da aritmética existente na época; porém, na era eletrônica em que vivemos, a prioridade deve ser o desenvolvimento e o uso de algoritmos para resolver problemas. Os autores citam cinco estratégias de resolução de problemas que julgam pertinentes serem abordadas nas escolas:

- Tentativa-e-erro: aplicação de operações pertinentes às informações dadas.

- Padrões: resolução de casos particulares, encontrando padrões que podem ser generalizados.

- Resolver um problema mais simples: resolução de um caso particular ou um recuo temporário de um problema complicado para uma versão resumida, podendo vir acompanhado do emprego de um padrão.

- Trabalhar em sentido inverso: partindo do resultado, realizar operações que desfazem as originais.

- Simulação: utilizada quando a solução do problema envolve a realização de um experimento e executá-lo não seja prático.

Cavalcanti (2001, p. 127) cita também a utilização do desenho "como recurso de interpretação do problema e como registro da estratégia de solução", podendo fornecer ao professor, pistas sobre como o estudante pensou e agiu para solucionar o problema. A mesma autora também cita a utilização do algoritmo convencional, ou seja, o Cálculo relacionado ao conteúdo envolvido no problema como "mais uma possibilidade de resolução" (p. 143).

Pesquisas demonstram que uma das estratégias mais utilizadas pelos alunos na resolução de problemas é o Cálculo formal (Dullius et al., 2011). Porém, a abordagem da Matemática através da resolução de problemas, permitindo que o aluno escolha o caminho que deseja percorrer para chegar à solução, possibilita ir além da linearidade do ensino tradicional à medida que o indivíduo resolvedor pode mobilizar diferentes conhecimentos para chegar a uma resposta.

Considerando os objetivos desta pesquisa, desenvolvemos uma investigação de abordagem predominantemente qualitativa, pois acreditamos na necessidade e importância de estudar a realidade sob o olhar do sujeito pesquisado, além de termos a visão do pesquisador. Segundo os procedimentos técnicos adotados para seu desenvolvimento, se constituiu em um estudo de caso, que permite aos pesquisadores, de acordo com Yin (2010, p. 24), reterem "as características holísticas e significativas dos eventos da vida real", e foi conduzida mediante a obtenção de dados a partir de diferentes fontes de evidência. Além disso, destaca o emprego desta metodologia "no exame dos eventos contemporâneos, mas quando os comportamentos relevantes não podem ser manipulados" (Yin, 2010, p. 32).

O contexto de investigação e desenvolvimento da proposta foram as seis escolas estaduais parceiras do Programa Observatório da Educação desenvolvido na Univates e a escola municipal em que a autora trabalha, sendo cinco dessas instituições localizadas em zonas urbanas e duas em zonas rurais, inseridas em municípios com número variado de habitantes, o que também está relacionado à quantidade de alunos atendidos.

Em reunião com o grupo de pesquisadores do Observatório da Educação definimos, dentre as séries participantes da Prova Brasil e SAEB, que a intervenção pedagógica seria realizada com as $7^{\mathrm{a}}$ e $8^{\mathrm{a}}$ séries da escola em que a primeira autora atua. Definida a turma, selecionamos oito problemas da Prova Brasil, levando em consideração os temas prioritários à série, segundo a Matriz de Referência (Brasil, 2008) do sistema avaliativo. Os mesmos foram resolvidos pelos alunos de $8^{\text {a }}$ série das escolas envolvidas, enfocando que, durante a resolução, descrevessem detalhadamente os procedimentos, ideias, raciocínios utilizados para que os mesmos fossem analisados, visando verificar as estratégias por eles mais utilizadas. Também foram orientados a tentar descrever, quando não conseguissem resolver algum problema, o motivo pelo qual não o fizeram.

As respostas dos alunos foram analisadas e classificadas a partir das seguintes categorias: Desenho, Cálculo, Tabelas ou gráficos, Tentativa e erro, Organizar padrões, Trabalhar em sentido inverso e Reduzir à unidade. Cabe salientar que a categorização das resoluções apresentadas pelos estudantes, tanto na coleta de dados inicial, quanto nas demais etapas da pesquisa, baseou-se em nossa experiência como professores-pesquisadores e na interpretação feita a partir do referencial teórico estudado, sendo passíveis outras formas de classificação por outro profissional. Ressaltamos ainda que algumas resoluções foram enquadradas em mais de uma categoria, por evidenciar mescla de estratégias.

A respeito desta etapa da investigação, destacamos a necessidade de criação de uma oitava categoria, que poderia ser denominada "Eliminação". Tal estratégia tem potencial para ser utilizada em questões ou problemas de múltipla escolha, onde, após a interpretação da situação, o estudante pode analisar as possíveis respostas e descartar, segundo critérios por ele estabelecidos, algumas alternativas. Chamou atenção ainda, o alto índice de alunos que apenas assinalaram uma resposta em determinados problemas, não sendo possível, 
na análise, identificar o motivo. Entretanto, pode revelar indícios de que estes alunos resolveram mentalmente ou, ainda, de que não entenderam tais problemas e assinalaram aleatoriamente uma alternativa, o que é possível quando elas são apresentadas, causando a falsa impressão de que o aluno conseguiu resolver o problema corretamente, caso acerte a resposta final. Mas está fora do escopo deste trabalho a análise detalhada destas situações.

De posse da análise das resoluções apresentadas pelos estudantes nesta etapa inicial de coleta de dados, iniciamos o planejamento e prática da intervenção pedagógica, foco de análise do presente trabalho, na qual os alunos foram estimulados a resolver problemas de diferentes conteúdos, utilizando, quando julgassem conveniente, estratégias alternativas. Ao final do período de experiência e contato dos alunos com a utilização das estratégias diversificadas, os mesmos resolveram novamente uma seleção de problemas, cujas resoluções foram posteriormente analisadas, e participaram de uma entrevista semiestruturada, onde puderam expor suas percepções acerca do trabalho. Com estes instrumentos, objetivamos coletar subsídios que nos fornecessem indícios de eficácia da proposta.

\section{Resultados e Discussão}

A intervenção pedagógica contou com a participação das turmas de $7^{\mathrm{a}}$ e $8^{\mathrm{a}}$ séries da Escola Municipal de Ensino Fundamental Roman Ross, localizada no município de Monte Belo do Sul, onde uma das pesquisadoras responsáveis atua. A escola está localizada na zona rural do município e é frequentada por alunos de várias comunidades do interior e também da sede, sendo o único educandário municipal a atender alunos das séries finais do Ensino Fundamental. A prática foi realizada em turno inverso à aula, visto que a maioria dos alunos das Séries Finais do Ensino Fundamental encontra-se na escola às quintas-feiras à tarde para participar de uma oficina de música, com duração de duas horas, lá permanecendo por mais uma hora e meia em outras atividades

As duas turmas eram compostas por 13 alunos, dos quais dois não participaram dos encontros, realizados em turno oposto ao de aula, ou seja, à tarde, pois trabalham nesse período. Dos 11, dois foram considerados desistentes por não terem participado dos últimos encontros. Alguns dos alunos que persistiram até o final também auxiliavam suas famílias nas propriedades rurais, porém dedicaram parte das tardes de quintas-feiras a participação na pesquisa.

A intervenção pedagógica consistiu em uma prática docente baseada na utilização de diferentes estratégias de resolução de problemas por parte dos estudantes da Educação Básica. No decorrer destas aulas, onde foram propostos problemas da Prova Brasil e SAEB, Olimpíadas Matemáticas, livros didáticos, sites, etc., utilizamos os passos para a resolução de problemas propostos por Polya (1995), insistindo na importância da leitura atenta e na identificação da incógnita para que ocorra uma correta interpretação das situações propostas. Nessa parte do processo, muitas vezes, foram realizadas discussões acerca dos dados apresentados pelos problemas e questionamentos aos alunos com o intuito de auxiliá-los na interpretação.

Porém, o foco da pesquisa estava no passo que correspondia ao estabelecimento de um plano, onde estimulamos a utilização de diversificadas estratégias, socializando aquelas que, porventura tenham sido utilizadas por alunos de outras turmas/escolas, ou mesmo as que surgiram na própria turma e, ainda, entre os bolsistas que auxiliaram no desenvolvimento da proposta. Na etapa de execução do plano, a ideia era que os estudantes ainda pudessem aperfeiçoar a estratégia traçada, acrescentassem detalhes e verificassem atentamente cada passo dado. Quanto ao retrospecto, ocorreu de forma a socializar e discutir as estratégias utilizadas para cada problema apresentado, levando os participantes a detectarem qual das formas se demonstrava mais eficaz.

Foram realizados 10 encontros nas dependências da escola, semanal ou quinzenalmente, às quintas-feiras, das $15 \mathrm{~h} 30 \mathrm{~min}$ às $17 \mathrm{~h}$ e neles, não foram introduzidos ou explicados conteúdos envolvidos nos problemas, considerando que a intenção foi estimular a busca por estratégias alternativas de resolução. $\mathrm{Na}$ maioria dos encontros, os alunos estiveram organizados em grupos, ora escolhidos por eles próprios, ora por alguma técnica ou dinâmica proposta pela professora que conduziu as aulas. A formação de pequenos grupos, fixos ou móveis, homogêneos ou heterogêneos permite ao professor, segundo Zabala (2006), deslocar-se e prestar auxílios adequados à necessidade de cada um. No primeiro encontro, suscitamos uma discussão acerca da resolução de problemas, onde procuramos evidenciar a opinião dos participantes quanto ao gosto por este tipo de atividade, possíveis dificuldades com relação ao processo e formas utilizadas para execução do mesmo. Também abordamos os passos para resolução de um problema, propostos por Polya (1995).

Cabe destacar que, na maioria dos encontros, adotamos a metodologia de leitura individual ou coletiva dos problemas, discussão focada na interpretação, elaboração de um plano e resolução, passando para a exposição dos caminhos utilizados e validação dos mesmos. Durante a discussão, levantamos questionamentos no intuito de incentivar a busca pela solução e auxiliar na interpretação do problema. Dante $(2009$, p. 63$)$ alerta que: "Não devemos dizer ao aluno aquilo que ele pode descobrir por si só. [...] Ao incentivar os alunos na resolução de um problema, devemos apresentar sugestões e insinuações, mas nunca apontar o caminho a ser seguido". Os momentos de auxílio aos alunos foram difíceis tanto individual quanto coletivamente. Desempenhar o papel de questionador e orientador não é uma tarefa fácil, já que as perguntas e direcionamentos devem tomar o cuidado de não fornecer respostas ou soluções. Além do mais, o impulso de auxiliar os alunos e livrá-los do "sofrimento" de não saber que rumo tomar, é muito grande.

As socializações tinham por objetivo que todos tomassem 
conhecimento das diferentes possibilidades de resolução, podendo assim escolher aquela que considerassem mais pertinente. Em alguns momentos a professora responsável apresentou para os alunos, estratégias não desenvolvidas por eles. Algumas vezes todos os grupos resolviam o mesmo problema e em outros, os mesmos eram diferentes, conforme o objetivo de cada momento. Somente após estas etapas é que um novo problema era proposto à turma. Nos últimos encontros, optamos por deixar a cargo de cada aluno ou grupo a exploração do problema, desde a leitura até a resolução, como forma de estimular a autonomia. O auxílio era dado, quando necessário, particularmente.

Em um dos encontros os alunos foram desafiados a elaborar problemas a partir de uma resposta dada, de uma figura e de uma pergunta, além de formular uma pergunta para uma situação que lhes foi apresentada. Cada grupo elaborou um problema, a partir de um desses aspectos, e os mesmos foram apresentados para leitura e discussão coletiva, resolução nos grupos e, quando necessário, reelaboração e nova resolução.

Apresentamos a seguir alguns dos problemas explorados durante a intervenção pedagógica, acompanhados de exemplos de resoluções desenvolvidas pelos alunos e análises das mesmas. Para análise das resoluções e exemplificação, o material escrito produzido pelos participantes foi enumerado, utilizando P1 para designar o participante 1, P2 para o participante 2 e assim, sucessivamente. Na Figura 1 apresentamos o Problema que foi proposto a um dos grupos formados no primeiro encontro com a respectiva resolução.

A primeira dificuldade do grupo foi na interpretação do problema, mas, após os questionamentos feitos, os alunos entenderam que a sequência de peças deveria continuar anotando ao lado da figura as quantidades de ladrilhos das peças seguintes ao perceber que aumentavam de 4 em 4 ladrilhos. Na sequência, somaram todas até chegar aos 330 ladrilhos, apagando as anotações referentes às peças a mais que haviam anotado.

Quando expuseram a resolução aos demais, sugeri a utilização de uma Tabela, onde poderiam anotar, na $3^{\text {a }}$ coluna, a quantidade total de ladrilhos utilizados a cada peça acrescentada na sequência. Dullius et al. (2011) também detectaram, em investigação desenvolvida acerca das estratégias utilizadas por participantes de uma Olimpíada Matemática, predomínio desta estratégia nas resoluções apresentadas para o mesmo problema.

Figura 1 - Problema proposto a P6 e P7 e resolução do grupo utilizando a estratégia de Tentativa e erro Usando ladrilhos quadrangulares, Ana decorou uma parede, conforme mostrado, parcialmente, na sequência de peças abaixo:

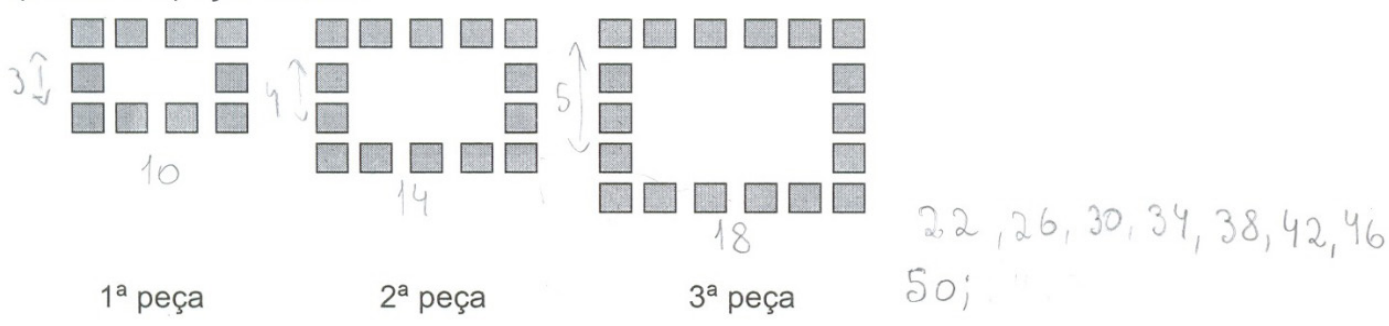

Sabe-se que Ana seguiu o mesmo padrão estabelecido na figura acima no desenho das demais peças com as quais decorou a parede. Quantos ladrilhos quadrangulares foram necessários na última peça de decoração, sabendo-se que Ana utilizou, ao todo, 330 ladrilhos?

Fonte: Problema extraído de Haetinger et al (2008).

O Problema 2, apresentado na Figura 2 com a resolução proposta por P9, também envolveu comparação de frações e foi resolvido através de Desenho pela maioria dos alunos e de forma correta. 
Figura 2 - Problema 2 e resolução de P9 utilizando a estratégia de Desenho

\section{2 - Quatro amigos, João, Pedro, Ana e Maria sairam juntos para fazer um passeio por um mesmo} caminho. Até agora, Joăo andou $6 / 8$ do caminho; Pedro, $9 / 12$; Ana, $3 / 8$ e Maria, $4 / 6$. Os amigos que agora estăo no mesmo ponto do caminho são:
b) João e Pedro.
b) Joăo e Ana.
c) Ana e Maria.
d) Pedro e Ana.

Fonte: Problema extraído de Brasil (2008)

$\mathrm{Na}$ resolução apresentada, os alunos transcreveram as frações, porém não as simplificaram, apenas desenharam-nas, na mesma sequência, comprovando que os trajetos de João e Pedro eram iguais. Apenas dois deles utilizaram o Cálculo,
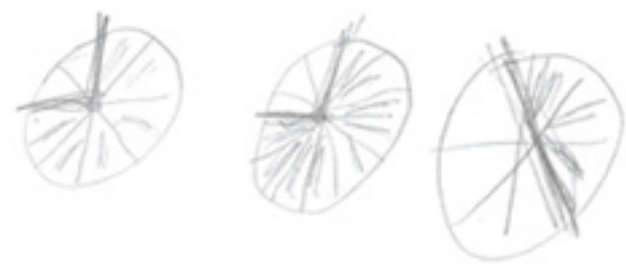

obtendo êxito também.

Na Figura 3, exemplificamos através da resolução de P9 a estratégia de Trabalhar em sentido inverso, utilizada corretamente pela maioria dos estudantes para resolver o Problema 3.

Figura 3 - Problema 3 e resolução de P9 utilizando a estratégia de Trabalhar em sentido inverso 3 - Pedro saiu de casa e fez compras em quatro lojas, cada uma num bairro diferente. Em cada uma gastou a metade do que possuia e, ao sair de cada uma das lojas, pagou R\$2,00 de estacionamento. Se, no final, Pedro ainda tinha R\$8,00, que quantia tinha ao sair de casa?
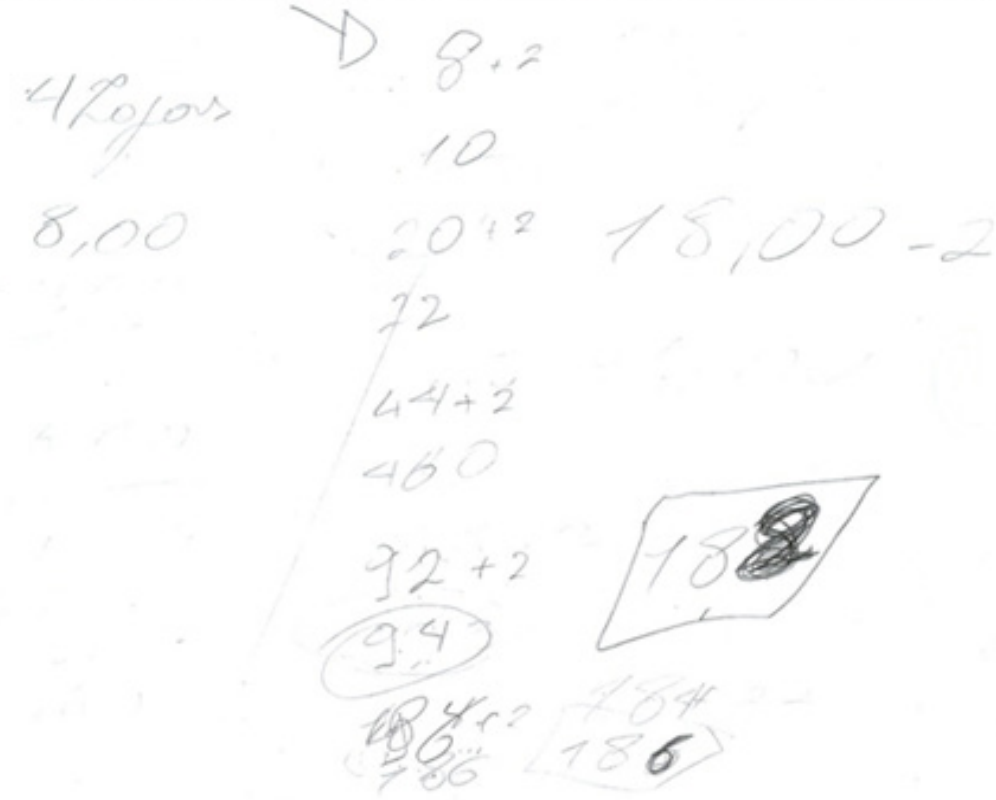

Fonte: Problema extraído de Sociedade Brasileira de Matemática [SBM] (2000)

Inicialmente, alguns grupos pensaram em diminuir o valor pago por Pedro em estacionamentos todo de uma vez, sem perceber que isso influenciaria no valor que ele teria ao entrar em cada loja. Foram feitos questionamentos e, por fim, exemplificado através de uma redução do problema, momento em que perceberam onde estava o erro. Caso optassem por realizar o Cálculo formal algébrico, provavelmente, seria necessário realizálo em partes e, sob nossa perspectiva, com grande chance de ocorrerem falhas no procedimento, que requer bastante atenção.

Os alunos relataram não saber como organizar o Cálculo formal para encontrar tal resposta, preferindo, portanto, a estratégia de Trabalhar em sentido inverso. Alguns ainda optaram pela Tentativa e erro, simulando valores que Pedro poderia possuir antes das compras e os gastos que teve. A partir do resultado obtido na primeira tentativa, analisaram se o próximo valor a ser testado deveria ser maior ou menor e partiram para novos testes até obter como resultado final os $\mathrm{R} \$$ 8,00 condicionados pelo problema, o que também possibilitou chegar à resposta correta.

O Problema 5 foi resolvido pela maioria dos alunos utilizando a estratégia por nós denominada Eliminação, que tem potencial de demonstrar-se eficaz em problemas de múltipla escolha, onde o indivíduo resolvedor precisa estabelecer critérios e eliminar alternativas que não se enquadrem nos mesmos. Em determinados casos, um critério basta e em outros, são necessárias outras análises e 
eliminações, até que reste apenas uma opção.

No exemplo apresentado na Figura 4, o aluno P2 esclarece os critérios utilizados, descartando primeiramente, planificações que não tivessem 6 faces (lados), ao que restaram as opções "C" e "D", obrigando-o a buscar um segundo critério, neste caso, o formato das faces.

Figura 4 - Problema 5 e resolução de P2 utilizando a estratégia de Eliminação 5 - Observe as figuras abaixo:
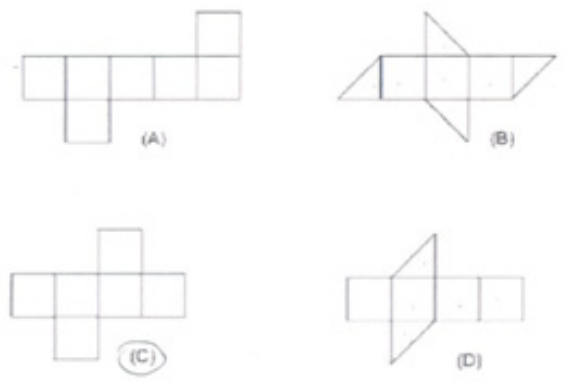

Entre elas, a planificação de uma caixa em forma de cubo é a figura:
a) (A)
b) (B)
क) (C)
d) (D)

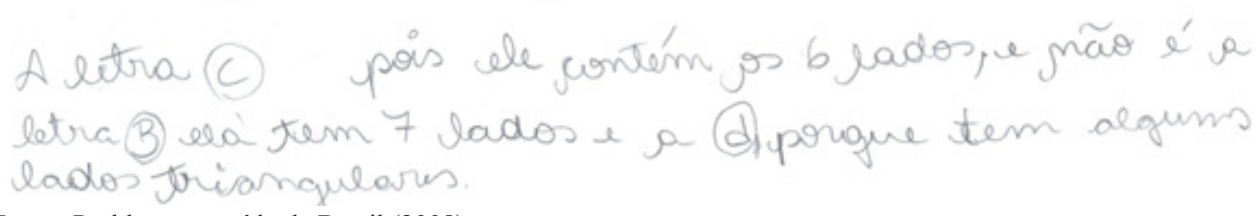

Fonte: Problema extraído de Brasil (2008).

$\mathrm{Na}$ Figura 5 exemplificamos a resolução do Problema 12, com utilização de Desenho. Os nove alunos presentes no encontro provavelmente utilizaram Desenho para resolver o problema por terem considerado mais fácil simular os passos de cada uma das personagens simultaneamente do que calcular.

Figura 5 - Problema 12 e resolução de P5 utilizando a estratégia de Desenho 12. - Ana começou a descer uma escada de 24 degraus no mesmo instante em que Beatriz começou a subi-la. Ana tinha descido $\frac{3}{4}$ da escada quando cruzou com Beatriz. No momento em que Ana terminar de descer, quantos degraus Beatriz ainda terá que subir?
a) 2
b) 6
c) 8
d) 10

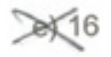

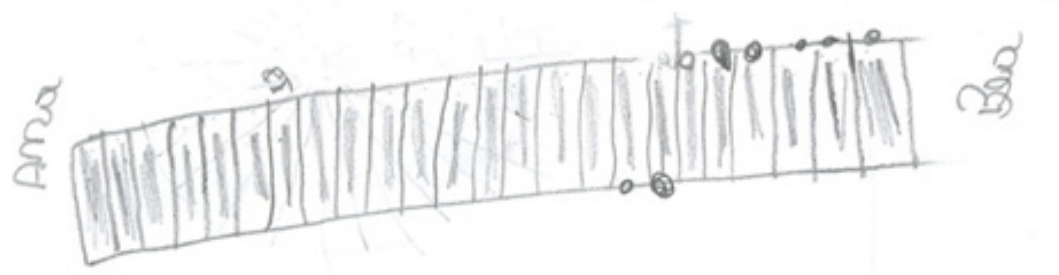

Fonte: Problema extraído de SBM (2011).

A maioria, após desenhar a escada, fez simulações até descobrir quantos passos Ana dava para cada passo de Beatriz, levando em consideração o momento do encontro das duas. Depois, continuaram "na mesma velocidade" até que Ana chegasse ao final da escada, contando os degraus faltantes para Beatriz. No exemplo apresentado na Figura 5, isso fica evidente pelos dois pontinhos feitos pelo aluno no lado contrário aos outros seis: segundo a explicação dada no quadro, ao expor aos demais a resolução, os riscos no centro dos degraus indicam aqueles que já foram percorridos por Ana e os pontinhos, representam os degraus já percorridos por Beatriz, sendo os primeiros seis antes do encontro e os outros dois, após. Feito isso, bastou contar os degraus que faltavam.

Novamente percebemos a importante contribuição que o
Desenho pode dar em situações que envolvem representações fracionárias. Na turma em que se encontram esses alunos, a manipulação de frações já poderia ter passado a um plano mais abstrato, pois, há vários anos eles lidam - ou pelo menos deveriam - satisfatoriamente com esse tipo de situação. Talvez esta estratégia tenha sido pouco explorada em anos anteriores, ocasionando dificuldades por parte dos alunos, ao lidar com a representação fracionária.

Na Figura 6, temos o Problema 15 acompanhado da resolução proposta por P9, juntamente com seu grupo, através da estratégia de Tentativa e erro, que foi utilizada corretamente por todos os alunos, sendo que alguns a associaram ao Desenho, usado para auxiliar na interpretação, que, segundo Cavalcanti (2001), é outra possibilidade para essa estratégia. 
Figura 6 - Problema 15 e resolução de P9 utilizando a estratégia de Tentativa e erro

$$
\begin{aligned}
& 15 \text { - Numa corrida com } 2011 \text { participantes, Dido chegou à frente do quádruplo do número de } \\
& \text { pessoas que chegaram à sua frente. Em que lugar chegou } 0 \text { Dido? }
\end{aligned}
$$

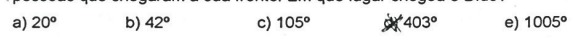

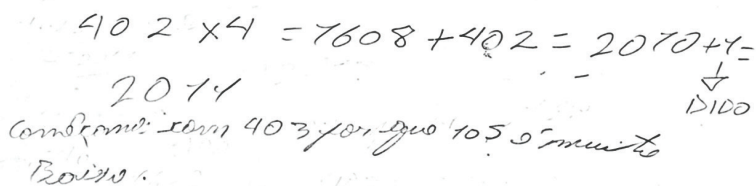

Fonte: Problema extraído de Instituto de Matemática Pura e Aplicada/ Olimpíada Brasileira de Matemática das Escolas Públicas [IMPA/ OBMEP] (2012).

O aluno optou por testar as alternativas multiplicando cada uma por 4, representando os participantes que chegaram atrás de Dido, adicionando o valor ao resultado e acrescentando o personagem principal. $\mathrm{O}$ fato de terem iniciado a tentativa pelo número 403 revela uma análise mais aprofundada por parte desse grupo, com relação aos demais, que testaram todas as possibilidades. O aluno relatou em sua resolução: “começamos com 403 porque 105 é muito baixo”, o que demonstra que estimou o possível resultado para cada opção antes de realizar o teste e comprovar a resposta.

Um grupo havia iniciado testes com outros números, parecendo não se dar conta de que havia alternativas e que a resposta devia ser uma delas. Ao questioná-los e ter certeza de que estavam testando possibilidades, apenas apontei as alternativas, momento em que seus componentes concluíram que não precisavam testar muitos números, mas apenas aqueles cinco. Nenhum grupo mencionou ou tentou organizar uma equação para resolver este problema.

Esse problema gerou muitas dúvidas, pois a maioria dos alunos não conseguia entender a condição "chegou à frente do quádruplo do número de pessoas que chegaram à sua frente". Foi necessário ler várias vezes e alguns compreenderam que, desenhando uma situação mais simples, poderiam interpretar mais facilmente este dado. Foi o caso de P6, que desenhou a Figura 7 e questionou: "Então é assim, aqui é o Dido: se quatro pessoas chegaram na frente dele, dezesseis chegaram atrás?"

Figura 7 - Desenho utilizado por P6 para auxiliar na interpretação do Problema 15

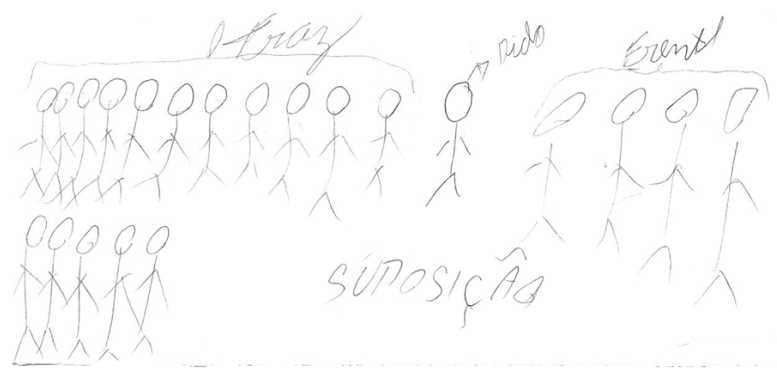

Quanto ao Problema 16, destacamos que a primeira questão foi resolvida corretamente por todos os alunos através de Desenho; porém, um dos grupos, apesar de ter acertado o desenvolvimento da resolução, errou ao destacar a resposta, como mostramos na Figura 8.

Figura 8 - Problema 16 e resolução de P7 utilizando as estratégias de Desenho e Tentativa e erro 16 - Na Figura 1, estäo representados os três primeiros termos de uma sequência de conjuntos de bolas que segue a lei de formação sugerida na figura.

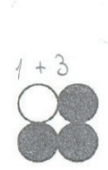

$1 .{ }^{\circ}$ termo

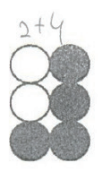

$2 \cdot{ }^{\circ}$ termo

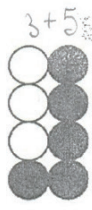

3. ${ }^{\circ}$ termo

FIGURA 1

a) Quantas bolas são necessárias para construir o $7 .^{\circ}$ termo da sequência?

b) Há um termo da sequência que tem um total de 108 bolas. Quantas bolas pretas têm esse termo?

め)
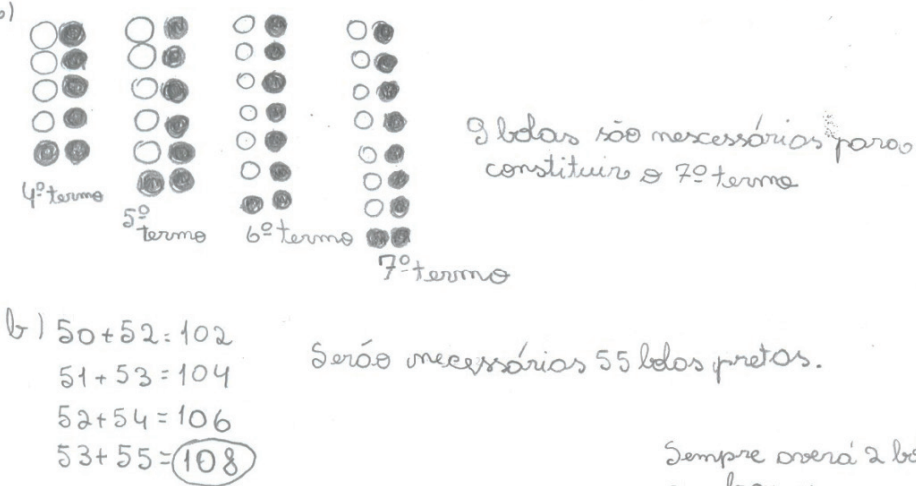

Seráo unecessários 55 bolos pretas.

Sempre overa' 2 bdos pretos a mpis

que broncos.

Fonte: Problema extraído de https://sites.google.com/site/desmatematicos/exames-provas/testes-intermedios---80-ano/2010-2011--3-periodo 
Nesse caso, evidencia-se mais uma vez a necessidade da verificação do resultado, pois se os alunos tivessem lido novamente a pergunta, é provável que percebessem que ela se referia ao número total de bolas no $7^{\circ}$ termo e não à quantidade de bolas pretas, que foi a resposta dada por P7. Talvez essa confusão tenha ocorrido devido à $2^{\mathrm{a}}$ pergunta, já que esta sim solicitava o número de bolas pretas de determinado termo.

Esse problema foi acertado por seis dos nove alunos que a resolveram e as estratégias variaram entre Tentativa e erro, como no exemplo da Figura 8, e Trabalhar em sentido inverso, onde os alunos dividiram o total de bolas (108) por 2 (número de colunas) e ao resultado, acrescentaram 1, pois há uma bola preta a mais que brancas.

Dentre os que resolveram por Tentativa e erro, três erraram, pois, nos últimos testes feitos, parecem ter se confundido e utilizado 4 bolas de diferença entre pretas e brancas e não 2, como fizeram inicialmente. Quanto à resolução daqueles que utilizaram esta estratégia de maneira correta, destacamos a provável análise realizada, pois, ao contrário do outro grupo, que organizou toda a sequência de termos, iniciaram os testes com o número 50 , provavelmente por terem percebido que, para resultar 108, seriam necessários dois termos maiores que 50.

Nas resoluções apresentadas para o Problema 19 evidenciamos a utilização da estratégia Tentativa e erro, como no exemplo da Figura 9 e também através da Redução à unidade ou desta, associada à Organização de padrões.

Figura 9 - Problema 19 e resolução de P2 utilizando a estratégia de Tentativa e erro

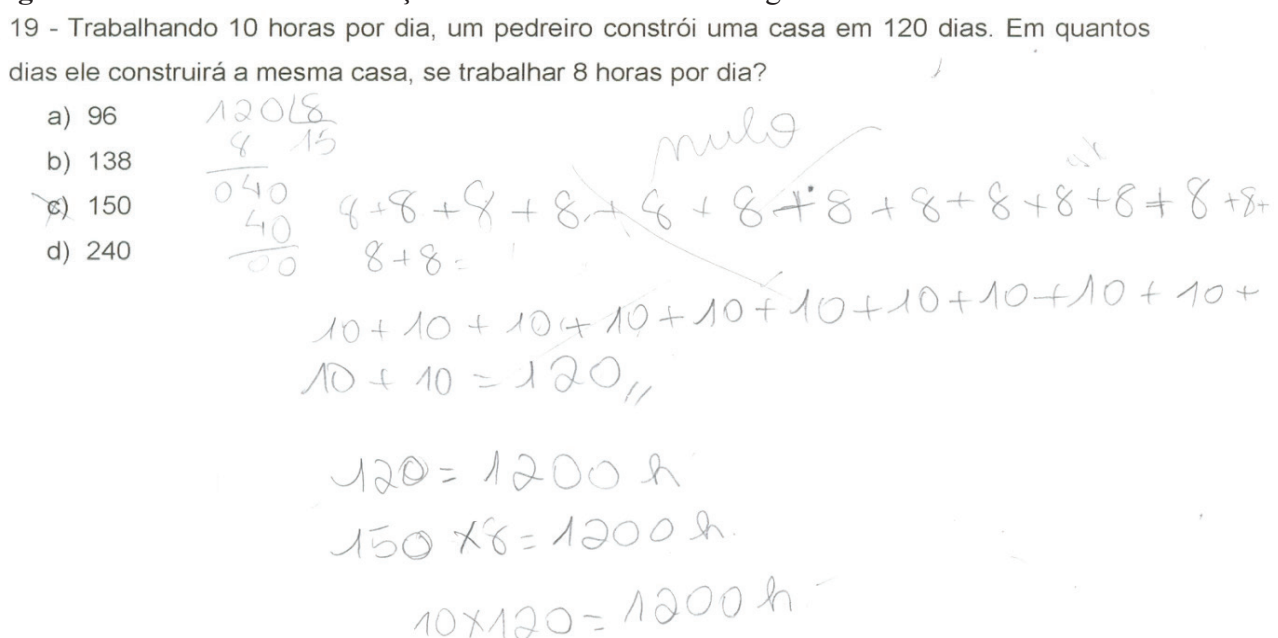

Fonte: Problema extraído de Brasil (2008)

Na resolução desenvolvida por esta dupla, percebe-se uma primeira tentativa de resolução abandonada através da palavra "nulo". Abaixo, evidencia-se a relação estabelecida entre os 120 dias trabalhados e o total de 1200 horas, calculadas mais abaixo $(10$ x $120=1200 \mathrm{~h})$. Os alunos também demonstraram que são necessários 150 dias trabalhando $8 \mathrm{~h}$ por dia, para completar as mesmas 1200 horas trabalhadas $(150 \times 8=$ 1200h). É provável que tenham testado também as demais alternativas ou eliminado, de antemão, pelo menos a primeira, por se tratar de menos dias do que na situação de 10 horas diárias trabalhadas.

Destacamos ainda a resolução apresentada por outra dupla que associou a Organização de padrões à estratégia de Redução à unidade, conforme apresentado na Figura 10.

Figura 10 - Problema 19 e resolução de P4 utilizando as estratégias de Organizar padrões e Reduzir à unidade
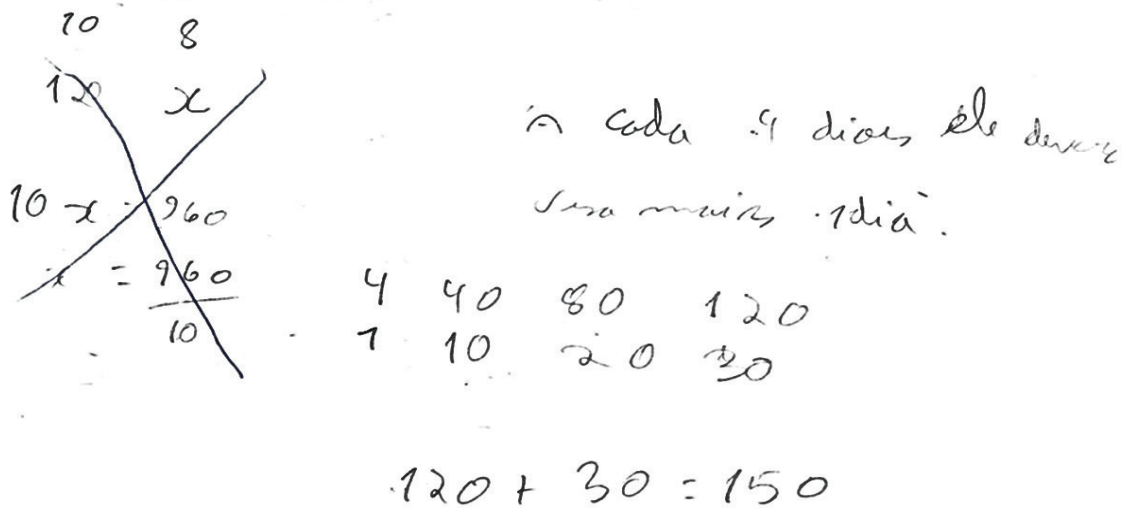

Fonte: Problema extraído de Brasil (2008) 
Os alunos que desenvolveram esta resolução haviam iniciado através de regra de três como se a situação fosse diretamente proporcional, porém, ao serem alertados quanto à verificação da resposta, detectaram a impossibilidade da resposta encontrada e traçaram um novo plano. Na resolução correta os alunos perceberam, conforme o que detalharam, que a cada 4 dias trabalhados com a carga horária reduzida, seria necessário trabalhar 1 dia a mais para compensar. Logo, fizeram as relações seguintes, baseadas nesta, como pode-se observar no exemplo, concluindo que seriam necessários 30 dias a mais de trabalho. Essa estratégia nos surpreendeu, pois não havíamos visualizado essa possibilidade de resolução, o que vem, mais uma vez, demonstrar a possibilidade de desenvolvimento de soluções criativas por parte dos alunos, quando permitidos a testar suas ideias.

Apresentamos ainda o Problema 20 que deixou de ser resolvido por apenas uma dupla. Os demais utilizaram a estratégia de Desenho como forma de verificar um comportamento para, em seguida, organizar os dados, no formato de uma Tabela. Um exemplo dessa forma de resolver é apresentado na Figura 11.

Figura 11 - Problema 20 e resolução de P2 utilizando as estratégias de Desenho e Tabela

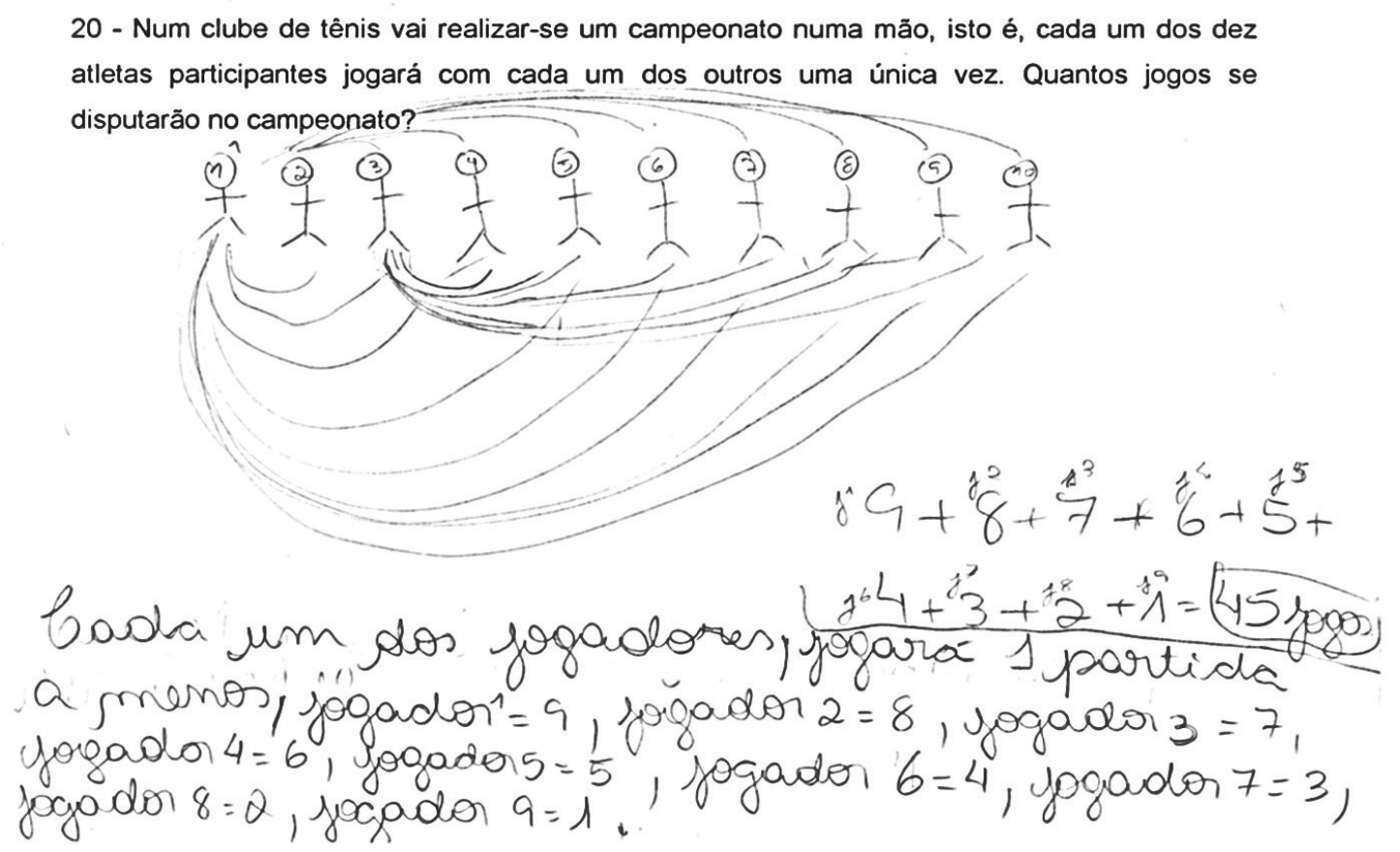

Fonte: Problema extraído de http://educamat.ese.ipcb.pt/0607/images/PDF/Mater_2C/sessao_03_estrategias.pdf

O aluno, juntamente com seu colega de dupla, desenhou a situação, ou seja, os 9 jogadores, simulando, através da união de 2 jogadores com uma linha, as possibilidades de jogos para os 3 primeiros jogadores, observando, a partir disso, que, para cada jogador, deveriam contar uma partida a menos que o anterior, já que precisavam considerar, por exemplo, apenas um jogo entre o jogador 1 e o jogador 2 . Ao observar essa regularidade, partiram para a organização dos dados em uma espécie de Tabela, provavelmente por considerar que seria menos trabalhoso do que realizar todas as possibilidades e depois contá-las. Na "Tabela", anotaram quantos jogos cada jogador teria, desconsiderando as repetições e, ao final, somaram.

É possível perceber que os participantes começaram a desenvolver mecanismos facilitadores para as resoluções, através da análise do plano traçado para cada problema. É positivo o fato de alguns alunos terem se dado conta de que não precisariam desenvolver todo o desenho, percebendo através dele, a existência de outra estratégia mais fácil e ágil de resolução.

Ao final do período de realização dos encontros, percebemos a evolução dos alunos no que tange à ampliação do repertório de estratégias utilizadas, em comparação ao que foi exposto por eles mesmos na primeira discussão, onde evidenciaram o Cálculo como principal forma de resolver problemas. Apesar disso, nos problemas propostos no decorrer da intervenção pedagógica, esta estratégia foi uma das menos utilizadas pelos participantes.

Também destacamos a mudança de postura, embora que pequena ainda, quanto à confiança e autonomia para testar planos traçados para a resolução, sendo que inicialmente, os alunos mostravam-se extremamente dependentes, questionando qual o tipo de conta a ser feita ou se o caminho pensado estava correto. Dante (2009, p. 57) destaca a importância de não fornecer respostas diretas à essas perguntas, o que resolveria o problema sem que o aluno precisasse pensar, apenas "executar as contas rápida e automaticamente". Segundo o autor, se o professor lançar outro questionamento, 
discutir o problema com o aluno ou mesmo sugerir que o faça com um colega, "os alunos continuam envolvidos com o problema e pouco a pouco vão perguntando menos e tornandose mais independentes e autônomos" (Dante, 2009, p 57). Na sequência, apresentaremos os resultados de uma coleta de dados obtida após a intervenção pedagógica, com os quais foi possível aferir a relevância da mesma.

Com o objetivo de obter indícios sobre a eficácia da intervenção pedagógica realizada com os alunos e obter mais subsídios para a análise dos dados, organizamos uma coleta de dados composta por dois instrumentos, sendo o primeiro uma guia de oito problemas previamente selecionados, propostos aos nove participantes da pesquisa para resolução individual. O segundo instrumento, aqui apresentado, consistiu em uma entrevista semiestruturada com os participantes, a qual foi gravada e transcrita ${ }^{1}$ para facilitar a análise. A mesma era composta por nove questões norteadoras, acrescidas, ocasionalmente, de perguntas para esclarecimentos ou aprofundamento das opiniões dos alunos quanto à participação nos encontros, a possíveis mudanças de postura no que tange à resolução de problemas e à utilização de estratégias diferenciadas no processo.

A maioria dos participantes demonstrou bastante timidez em participar da entrevista, mesmo que estivéssemos gravando apenas o áudio. Após duas ou três entrevistas, optamos por ter em mãos o material produzido pelos alunos durante os encontros para comentá-lo, retomar o que haviam feito, numa tentativa de fazê-los expressar mais opiniões acerca da intervenção pedagógica.

Durante a entrevista, lembramos que no primeiro encontro a maioria, ao falar de formas de resolver problemas, citou apenas o Cálculo formal, apesar de saber da existência de outras formas. Questionados se passaram a conhecer outras formas, muitos alunos negaram ou citaram apenas uma ou duas, mas, no decorrer da conversa, lembrando dos problemas resolvidos nos encontros, passaram a citá-las. Alguns ressaltaram que conheceram tais estratégias nos encontros, pois não faziam uso das mesmas anteriormente, como por exemplo P8, enquanto discutíamos o Problema 1 da coleta de dados final:

Pesquisadora: Por exemplo, tu usaste um Cálculo para fazer isso ou uma equação.

P8: Ia contando os dias e quantos dias que fazia cada dia e ia somando. Ai deu isso

Pesquisadora: Isso, tu concordas que não é Cálculo, não é uma equação que tu pegaste ou uma fórmula pronta em que tu trocaste letras por números para resolver?

P8: Não.

Pesquisadora: Isso aqui a gente chama, na verdade, tua organização é de uma tabela, mas tu foste fazendo as tentativas de ver quantos abdominais a cada dia, tu foste simulando todos os valores. Então isso não é Cálculo formal isso é uma mistura de tentativa e erro com tabela. Essa é uma estratégia que tu usaste. Tu conhecias isso? Tu costumavas resolver problemas desse jeito?

P8: Desse jeito não, depois que eu vim nas aulas de tarde eu aprendi.

A terceira, a quinta e a sexta perguntas tiveram foco na opinião dos alunos quanto à importância de conhecer e utilizar outras maneiras de resolver problemas e à contribuição das mesmas no processo de resolução. Foi unânime entre os alunos a opinião de que o conhecimento de outras estratégias de resolução de problemas pode contribuir, auxiliar na melhoria da forma de resolver problemas ou torná-la mais fáceis. P10 relatou, por exemplo, que ao esquecer de uma fórmula, pode recorrer a outra estratégia para resolver problemas em aula:

Pesquisadora: Conhecer essas formas, essas formas diferentes te ajuda a resolver problemas melhor?

P10: Ajuda, bastante eu acho. [...] Porque assim, se tu não vai lembrar, por exemplo, numa prova, talvez do Teorema de Pitágoras, alguma coisa assim, daí isso pode ajudar.

Alguns alunos destacaram também a utilização das estratégias em situações com as quais se depararam nas atividades da Matemática do currículo escolar:

P5: Tinha na apostila alguns problemas que eram parecidos e aí a gente tentava.

Pesquisadora: Aí tu conseguiste transportar teus conhecimentos daqui?

P5: É, do projeto pra sala de aula.

Pelo relato de $\mathrm{P} 3$, podemos inferir que considera que as estratégias serão mais úteis para os problemas da vida cotidiana, aqueles que terá que enfrentar e resolver fora da escola.

Pesquisadora: $\mathrm{Tu}$ achas importante poder usar essas estratégias?

P3: Claro que é!

Pesquisadora: Por quê?

P3: Porque pode usar no dia, geralmente, no futuro.

Por fim, questionamos a respeito da perspectiva dos alunos quanto à participação nos encontros, buscando uma opinião geral quanto ao aproveitamento dos mesmos, quanto às possíveis influências para as vidas dos participantes, tanto em sala de aula quanto fora dela. Percebemos que os alunos, de um modo geral, se manifestaram positivamente.

P4: Eu gostei, porque deu mais conhecimento.

P5: Eu achei que foi bom, valeu a pena, eu achei que fosse mais centrado mais em fazer Cálculos, acho que foi bom. Também vai ser mais fácil quando a gente for pra oitava, pro primeiro ano... usar outras formas.

P10: Acho que foi bom, que ajudou nas aulas, nas resoluções de problemas. Gostei bastante, valeu a pena...

No relato de P5, fica evidente a preferência pela utilização de estratégias diferenciadas na resolução de problemas, quando revela que gostou de ter participado dos encontros por não ter sido priorizado o Cálculo na resolução de problemas.

\section{Conclusão}

Preocupados com a forma como a resolução de problemas vem sendo abordada e com o pouco êxito atingido pelos alunos, decidimos investigar o potencial da utilização de diferentes

1 Transcrevemos as falas fazendo pequenas correções gramaticais, quando a forma original tornaria o texto de difícil compreensão. 
estratégias de resolução de problemas, independentemente da abordagem de conteúdos específicos da Matemática escolar. Nos dados coletados inicialmente no intuito de investigar as diferentes estratégias utilizadas pelos alunos na resolução de problemas matemáticos, verificamos o predomínio do Cálculo formal como forma de resolver problemas, ocasionando, em alguns casos, baixo índice de acerto.

Durante a intervenção pedagógica, analisando o material produzido pelos alunos participantes, verificamos que os mesmos foram capazes de utilizar, de forma eficaz, uma grande variedade de estratégias de resolução de problemas, tais como: Tentativa e erro, Desenho, Tabelas, Trabalho em sentido inverso, Reduzir à unidade, Organização de padrões e Eliminação, algumas delas sequer pensadas por nós professores, evidenciando assim, o estímulo à criatividade e autonomia proporcionado por esta forma de trabalho. Creditamos o fato de terem utilizado mais e melhor uma ampla gama de estratégias de resolução de problemas ao estímulo oferecido para que isso ocorresse e que tem sido um dos objetivos perseguidos desde o início da pesquisa. Os alunos utilizaram as estratégias compartilhadas, principalmente o Desenho, inclusive para auxiliar na interpretação de determinadas situações.

Esta diferença com relação à coleta de dados inicial pode estar relacionada ao fato de, em momento algum ter sido exigida a utilização de algoritmos formais ou mesmo, discutido ou apresentado um conteúdo da Matemática escolar. Dessa forma, portanto, conseguiram ampliar o repertório de estratégias passíveis de serem utilizadas, conforme relatado por vários alunos na entrevista. Na oportunidade evidenciouse também, preferência da maioria, pela utilização das formas alternativas de resolução, sob a justificativa principal da dificuldade em lembrar ou saber como e em quais casos aplicar certos algoritmos, o que reforça a contribuição desta forma de trabalho para a obtenção de êxito na resolução de problemas, considerando que sem essa possibilidade, muitos sequer resolveriam determinados problemas.

Analisando a transcrição das entrevistas realizadas ao final dos encontros, fica clara a adesão dos participantes à proposta, quando sinalizam a importância de conhecer e poder fazer uso das estratégias que foram compartilhadas. Alguns alunos, como por exemplo A2, A5 e A9, confirmaram a utilização dos conhecimentos adquiridos e compartilhados durante a intervenção pedagógica, nas aulas de Matemática e mesmo em avaliações da disciplina. Vários dos participantes atribuíram a este conhecimento o fato de ter aumentado o gosto, antes quase inexistente, pela resolução de problemas.

Salientamos que não temos a pretensão de sugerir a eliminação do ensino de conteúdos formais da Matemática escolar, mas consideramos importante que, simultaneamente ao estudo de tais conteúdos, os alunos tenham também a oportunidade de conhecer as diversas formas passíveis de serem utilizadas, podendo optar, no momento de elaborar um plano de resolução, pela estratégia que julgar mais conveniente, por aquela que avaliar como facilitadora de seu processo. Ao se depararem, por exemplo, com problemas, que envolvem conteúdos de um ano inteiro ou mais, os alunos podem esquecer de detalhes que farão toda a diferença na obtenção de respostas corretas, ao utilizar o Cálculo formal, ao passo que, conhecendo estratégias, podem adaptá-las a diferentes contextos e obter êxito.

\section{Referências}

Brasil. Ministério da Educação. (2008). PDE : Plano de Desenvolvimento da Educação: Prova Brasil: Ensino Fundamental: matrizes de referência, tópicos e descritores. Brasília: MEC/SEB; Inep.

Brasil. Secretaria de Educação Fundamental. (1998). Parâmetros Curriculares Nacionais: Matemática. Brasília: MEC/SEF.

Cavalcanti, C. (2001) Diferentes formas de resolver problemas. In: Smole, K. S. \& Diniz, M. I. (Orgs.). Ler, escrever e resolver problemas: Habilidades básicas para aprender matemática. (pp. 121 - 149). Porto Alegre: Artmed.

D’Ambrosio, B. S. (n.d.) Como ensinar matemática hoje? Recuperado em 11 janeiro, 2012, de: http://educadores. diaadia.pr.gov.br/arquivos/File/2010/artigos teses/ MATEMATICA/Artigo_Beatriz.pdf

Dante, L. (2000). Didática da resolução de problemas de Matemática: $1^{\mathrm{a}}$ a $5^{\mathrm{a}}$ series. São Paulo: Ática.

Dante, L. (2009). Formulação e resolução de problemas de Matemática: teoria e prática. São Paulo: Ática.

Dullius, M. M., Quartieri, M. T., Haetinger, C., Furlanetto, V., Endler, G. M., Eidelwein, G. M. \& Althaus, N. (2011). Estrategias utilizadas en la resolución de problemas matemáticos. Revista chilena de educación científica, 10, pp. 23-32.

Haetinger, C., Dullius, M. M., Quartieri, M. T., Rehfeldt, M., Gish, T., Cenci, D., Kern, C. \& Storck, E. R. (Orgs). (2008). Anais da XI Olimpiada Matemática da UNIVATES, 10 de setembro de 2008. Lajeado: UNIVATES.

Instituto de Matemática Pura e Aplicada/Olimpíada Brasileira de Matemática das Escolas Públicas (2012). Banco de Questões 2012. Rio de Janeiro: IMPA.

Musser, G. L. \& Shaughnessy, J. M. (1997). Estratégias de resolução de problemas na matemática escolar. In: Krulik, S. \& Reys, R. E. (Orgs.) A resolução de problemas na matemática escolar. Tradução de Hygino H. Domingues e Olga Corbo. (pp. 188 - 201). São Paulo: Atual.

Onuchic, L. de L. R. \& Allevato, N. S. G. (2004). Novas reflexões sobre o ensino-aprendizagem de Matemática através da Resolução de Problemas. In: Bicudo, M. A. V. \& Borba, M. de C. (Orgs.). Educação matemática: pesquisa em movimento. (pp. 213 - 231) São Paulo, Brasil: Cortez.

Polya, G. (1995). A arte de resolver problemas: um novo aspecto do método matemático. Tradução e adaptação de Heitor Lisboa de Araújo. Rio de Janeiro: Interciência.

Sociedade Brasileira de Matemática. (2000). XXI Olimpíada Brasileira de Matemática, Primeira Fase - Nível 2. Revista Eureka!, 7, 7 - 9. Recuperado em 18 março, 2012, de http:// www.obm.org.br/export/sites/default/revista eureka/docs/ eureka7.pdf

Sociedade Brasileira de Matemática. (2011). XXXII Olimpíada Brasileira de Matemática: Problemas e soluções da Primeira Fase. Revista Eureka!, 34, 3 - 14. Recuperado em 18 março, 
FURLANETTO, V.; DULLIUS, M.M.

2012, de http://www.obm.org.br/export/sites/default/revista eureka/docs/eureka34.pdf

Yin, R. K. (2010). Estudo de caso: planejamento e métodos. Tradução de Ana Thorell. 4. ed. Porto Alegre: Bookman.
Zabala, A. (2003). Os enfoques didáticos. In: Cool, C. et al. (Orgs.) O Construtivismo na sala de aula. Tradução de Cláudia Schilling. (pp. 153 - 196). São Paulo: Ática. 